\title{
The Improvement of Quality Management Economics
}

\author{
Xiaojiao Yin \\ NanChang Institute of Science \& Technology
}

\begin{abstract}
Keywords: Economic management; Economics; Economic law; Quality management
\end{abstract}
\begin{abstract}
With the implementation of ISO quality management system in enterprise, the quality economic is fully reflected. As one of the important concepts of quality management system quality cost provides theoretical basis for the enterprise from accounting measurement and number accounting. In addition to the quality cost analysis and control, the effect of quality economic in the enterprise should also be combined with enterprise's development strategy, taking consideration of enterprise survival and long-term development. The problems of quality economics is a difficult problem troubling national theoretical, education and industry cycles for long time.
\end{abstract}

\section{Introduction}

In the increasingly fierce market competition environment, more and more enterprises realize the importance of quality for their own survival and development. The generation of ISO9000 standard and its promotion in the enterprise reflect the internationalization and standardization of quality management system. In the increasingly open market competition, the domestic enterprises have to catch up the product and service quality requirements in international market. "Implementing standards", "certification", "ISO" and other words that are related to the quality appear in the enterprise strategic development and practice more and more frequently. "To get the efficiency from quality" is the slogan presenting the quality target of the enterprises. It reflects not only the inner link between the quality and performance also reveals that quality is not just a collection of some characteristics of a product, but also has economics for enterprises and consumers.

Quality economic analysis is to conduct economic analysis and economic benefit evaluation of quality management mainly based on analysis of the relationship between the products quality and input and output, in order to meet customers' needs and create the best economic benefit for the enterprise. Namely from the perspective of economy, using cost-benefit analysis method to analyze and evaluate the improvement measures for different quality levels and different management plans, picking out the solutions both meeting the demand of customers and costing lower. Obviously, to improve the quality economics, economic and quality improvement should be done, that is, the quality of products shall be higher than quality requirement without one-sided pursuit of unrealistic so-called "high quality" deviating from the customer requirements. According to the views of quality economic research, any too high or too low quality is not economical, resulting in increased costs and poor economic benefits.

\section{Necessary for Researching the Problems of Quality Economics}

Until now, the scholars of countries have many different concepts of quality economics, and their formulations are also very divergent.

1. Definition of "quality cost": "all the costs occurred on products quality, including the cost due to the loss caused by quality problems and the costs to ensure improving products quality."

2. Some scholars in China propose the concept "economics of products" and define it as "reasonable products life cycle cost". They think that "production conditions: life cycle cost includes the costs sum of $\mathrm{R} \& \mathrm{D}$ process, manufacturing process, circulating process and disposition cost. It is one of the main quality characteristics to meet the needs of customers and society."

3. Famous cost quality management expert Kaoru Ishikawa thinks that the narrow quality characteristics include: performance purity, strength, size, tolerance, appearance, reliability, reject ratio. And he thinks that the generalized quality includes: (1) the characteristics of narrow quality; 
(2) cost, price, profit; (3) output, sales, delivery and so on; (4) the characteristics after leaving the factory.

\section{Economics of Quality}

Considering as a kind of economic entity, quality will generate the final revenue or loss through cost and income. The performance of quality includes the tangible increasing income and reducing expenditure and also the intangible business reputation and brand effect. Quality contribution for the enterprise includes two aspects: one is acknowledgement of customers and the market, increasing market share and expanding sales; secondly, reducing the reputation loss, compensation loss caused by quality problems. High quality products can bring benefits for customers and the society. Quality loss can be interpreted as in the whole product life cycle, the sum of loss for the manufacturer, consumers and the society due to unqualified products, involving the benefits of various aspects. American quality management master Juran considers the cost of inferior-quality product as "a gold ore", which can be exploited by quality control, so "the great potential to improve the economic benefits is contained in the products quality" is the maxim for enterprises.

Just because quality is beneficial but consuming some resources, the highest quality is not always the best. Because the excessive quality with unreasonable pursuance exceed the actual demand of the customers, making them spend more money, which cause unnecessary loss, which is usually called "residual mass".

\section{Improved Method for Quality Management Economics}

One of the basic starting point for modern quality management is the enterprise provide the required products and services of users depending on economy and production, emphasizing the unification of quality and economy, which is one outstanding sign that modern quality management distinguishing traditional quality management. A lot of practice at home and abroad proves that good quality management must improve the economic benefits of enterprises.

Quality economic analysis is to conduct economic analysis and economic benefit evaluation of quality management mainly based on analysis of the relationship between the products quality and input and output, in order to meet customers' needs and create the best economic benefit for the enterprise. Namely from the perspective of economy, using cost-benefit analysis method to analyze and evaluate the improvement measures for different quality levels and different management plans, picking out the solutions both meeting the demand of customers and costing lower. Obviously, to improve the quality economics, economic and quality improvement should be done, that is, the quality of products shall be higher than quality requirement without one-sided pursuit of unrealistic so-called "high quality" deviating from the customer requirements. According to the views of quality economic research, any too high or too low quality is not economical, resulting in increased costs and poor economic benefits.

There are two basic elements for improving quality management economics: improve customer satisfaction and reduce the resource cost, which are also two principles for improving quality management economics. After applying cost management of quality, the degree of improvement still needs discussion and analysis.

\section{Conclusion}

Quality problem is actually an economic problem. The analysis and management of quality economics is an important step for the success of enterprises quality economics. The emphasis and research is the weak link for enterprise development, and also the economic task an important way to exploit the potentialities, reduce the cost continually and improve the quality. But quality cost is not the whole contents of quality economics. Enterprises should start from the industry and the actual development, making the strategy involving quality management, to guide and promote the quality management work of enterprises. The paper provides theoretical basis for enterprises based 
on accounting measurement and number accounting, setting forth in addition to quality cost analysis and control, the quality economics should be combined with the strategy of enterprises, considering long term development of enterprises.

\section{References}

[1] Lohr K N, Schroeder S A. A strategy for quality assurance in Medicare. [J]. New England Journal of Medicine, 1990, 322(322):707-12.

[2] Iglehart J K. The National Committee for Quality Assurance. [J]. New England Journal of Medicine, 1996, 335(13):995-999.

[3] Shaw E, Kline R, Gillin M, et al. Radiation Therapy Oncology Group: radiosurgery quality assurance guidelines. [J]. International Journal of Radiation Oncology Biology Physics, 1993, 27(5):1231-1239.

[4] Director K N L D. Medicare: a strategy for quality assurance.[J]. Journal of Quality Assurance A Publication of the National Association of Quality Assurance Professionals, 1990, 13(1):10-3.

[5] Kouloulias V E. Quality assurance in radiotherapy. [J]. European Journal of Cancer, 2015, 44(4):477-492.

[6] Sroufe R, Curkovic S. An examination of ISO 9000:2000 and supply chain quality assurance [J]. Journal of Operations Management, 2008, 26(4):503-520.

[7] Holleran E, Bredahl M E, Zaibet L. Private incentives for adopting food safety and quality assurance[J]. Food Policy, 1999, 24(6):669-683.

[8] Klein E E, Hanley J J. Task Group 142 report: quality assurance of medical accelerators. [J]. Medical Physics, 2009, 36(9):4197.

[9] Laurie C C, Doheny K F, Mirel D B, et al. Quality control and quality assurance in genotypic data for genome-wide association studies.[J]. Genetic Epidemiology, 2010, 34(6):591-602.

[10] Cronenwett J L, Likosky D S, Russell M T, et al. A regional registry for quality assurance and improvement: The Vascular Study Group of Northern New England (VSGNNE) [J]. Journal of Vascular Surgery, 2007, 46(6):1101-2.

[11] Bostwick D G. Quality assurance in the laboratory diagnosis of prostate cancer [J]. Cancer, 1995, 75(S7):1994-1999.

[12]Resch-Genger U. Standardization and Quality Assurance in Fluorescence Measurements I [J]. Journal of the American Ceramic Society, 1988, 71(3):157-166. 